\title{
Molecular Identification of Tumor-Derived Extracellular Vesicles using Thermophoresis-Mediated DNA Computation
}

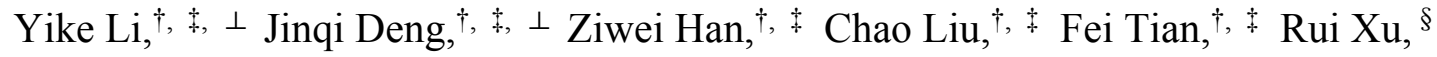

Da Han, ${ }^{*, \S}$ Shaohua Zhang, ${ }^{*, \#}$ and Jiashu Sun $*, \dagger,+$

${ }^{\dagger}$ Beijing Engineering Research Center for BioNanotechnology, CAS Key Laboratory of Standardization and Measurement for Nanotechnology, CAS Center for Excellence in Nanoscience, National Center for Nanoscience and Technology, Beijing 100190, China.

$¥$ School of Future Technology, University of Chinese Academy of Sciences, Beijing 100049, China.

$\S$ Institute of Molecular Medicine and Shanghai Key Laboratory for Nucleic Acid Chemistry and Nanomedicine, State Key Laboratory of Oncogenes and Related Genes, Renji Hospital, School of Medicine, Shanghai Jiao Tong University, Shanghai, 200127, China.

\# Department of Breast Cancer, The Fifth Medical Centre, Chinese PLA General Hospital, Beijing 100071, China.

Da Han:dahan@sjtu.edu.cn

Shaohua Zhang: zhangshaohua@csco.org.cn

Jiashu Sun: sunjs@nanoctr.cn 
Materials. Bovine serum albumin (BSA), yeast tRNA and glucose were purchased from MesGen (China). NaCl, EDTA, $\mathrm{MgCl}_{2}$ and Triton ${ }^{\mathrm{TM}} \mathrm{X}-100$ were purchased from Sigma (USA). TBE buffer and Tris-HCl buffer were purchased from Solarbio (China). DNA oligonucleotides, DNA staining dye GelRed, $\mathrm{Mg}(\mathrm{Ac})_{2}$ and agarose were purchased from Sangon Biotech (China). Streptavidin-coated polystyrene microbeads (1.8 $\mu \mathrm{m}$ in diameter) were purchased from Spherotech (USA). Anti-CD63 antibody was purchased from Abcam (UK). DiI (ex/em: 549/565 nm) was purchased from ThermoFisher (USA). Dulbecco's modified Eagle's medium (DMEM), RPMI-1640 medium, Leibovitz's L-15 medium, fetal bovine serum (FBS), penicillin-streptomycin, phosphate buffered saline (PBS) and Dulbecco's PBS (DPBS) were purchased from Gibco (USA). MEGM BulletKit (CC-3151 \& CC-4136) medium was purchased from LONZA (USA).

Preparation of DNA probes. EpCAM-S- $\mathrm{T}_{1}$, HER2-S- $\mathrm{T}_{2}$, Connector, $\mathrm{H}_{1}$ and $\mathrm{H}_{2}$ were dissolved in DPBS-Mg buffer (DPBS containing $12.5 \mathrm{mM} \mathrm{Mg}(\mathrm{Ac})_{2}$ ) to a concentration of $10 \mu \mathrm{M}$. EpCAM-S-T 1, HER2-S-T 2 and Connector were heated for 5 min at $95{ }^{\circ} \mathrm{C}$ and cooled to $25{ }^{\circ} \mathrm{C} . \mathrm{H}_{1}$ and $\mathrm{H}_{2}$ were heated for $10 \mathrm{~min}$ at $60{ }^{\circ} \mathrm{C}$ to promote dissolution and cooled to $25^{\circ} \mathrm{C}$. Biotinylated CD63 aptamer was dissolved at $100 \mu \mathrm{M}$ in $1 \times \mathrm{PBS}$, heated for $5 \mathrm{~min}$ at $95{ }^{\circ} \mathrm{C}$ and cooled to $25^{\circ} \mathrm{C}$.

Validation of AND gate in buffer. To verify the associative toehold-triggered HCR upon the joint between two individual Apt-S-T probes, agarose gel 
electrophoresis was conducted for 5 different samples (Figure S2). L1: the mixture of $1 \mu \mathrm{M} \mathrm{H} \mathrm{H}_{1}$ probe and $1 \mu \mathrm{M} \mathrm{H}_{2}$ probe incubated for $1.5 \mathrm{~h}$ at $4{ }^{\circ} \mathrm{C}$; L2: the mixture of $1 \mu \mathrm{M}$ single stranded DNA (ssDNA) initiator, $1 \mu \mathrm{M} \mathrm{H} \mathrm{H}_{1}$ probe and $1 \mu \mathrm{M} \mathrm{H}_{2}$ probe incubated for $1.5 \mathrm{~h}$ at $4{ }^{\circ} \mathrm{C}$; L3: the mixture of $1 \mu \mathrm{M}$ EpCAM-S-T $1,1 \mu \mathrm{M}$ HER2-S- $\mathrm{T}_{2}$ and $1 \mu \mathrm{M}$ Connector incubated for $1 \mathrm{~h}$ at $4{ }^{\circ} \mathrm{C}$, followed by addition of $1 \mu \mathrm{M} \mathrm{H}_{1}$ probe and $1 \mu \mathrm{M} \mathrm{H}_{2}$ probe and subsequent incubation for $1.5 \mathrm{~h}$ at $4{ }^{\circ} \mathrm{C}$; $\mathrm{L} 4$ : the mixture of $1 \mu \mathrm{M}$ EpCAM-S-T ${ }_{1}$ and $1 \mu \mathrm{M}$ HER2-S- $\mathrm{T}_{2}$ incubated for $1 \mathrm{~h}$ at $4{ }^{\circ} \mathrm{C}$, followed by addition of $1 \mu \mathrm{M} \mathrm{H} \mathrm{H}_{1}$ probe and $1 \mu \mathrm{M} \mathrm{H} \mathrm{H}_{2}$ probe and subsequent incubation for $1.5 \mathrm{~h}$ at $4{ }^{\circ} \mathrm{C}$; L5: the mixture of $1 \mu \mathrm{M}$ EpCAM-S-T $1,1 \mu \mathrm{M} \mathrm{H}_{1}$ probe and $1 \mu \mathrm{M} \mathrm{H} \mathrm{H}_{2}$ probe incubated for $1.5 \mathrm{~h}$ at $4{ }^{\circ} \mathrm{C} . \mathrm{H}_{1}$ probe was labeled with $\mathrm{Cy} 5$ and BHQ3. Each sample was mixed with loading buffer and analyzed in $2 \%$ agarose gel (made in $0.5 \times \mathrm{TBE}$ containing $10 \mathrm{mM} \mathrm{MgCl}_{2}$ ). The electrophoresis was conducted at a constant voltage of $75 \mathrm{~V}$ for $3 \mathrm{~h}$ at $4{ }^{\circ} \mathrm{C}$. The gel was scanned by a UV transilluminator (Bio-Rad, USA) after stained with GelRed. Fluorescence intensities for these 5 samples (100 $\mu \mathrm{L}$ for each) were also quantified at $670 \mathrm{~nm}$ using a microplate reader (Synergy H1, Biotek, USA) (Figure 2a).

Formation of HCR assembly by DNA computation. As depicted in Figure S2, both L2 and L3 showed significantly large amounts of HCR products. The fluorescence intensity measured at Cy5 channel for L2 was 1.9-fold higher than that for L3 (Figure 2a), indicating that the catalytic efficiency for HCR reaction of aptamer assembly was lower than that of ssDNA initiator. One reason is that the 
assembly yield of EpCAM-S-T 1 , HER2-S-T 2 and Connector is not $100 \%$, which lowers their effective concentrations for triggering HCR. In addition, the aptamer assembly needs to form an associated toehold structure that is composed of "nicked" $\mathrm{T}_{1}$ and $\mathrm{T}_{2}$ as an equivalent to an intact ssDNA initiator. The structural flexibility of $T_{1}$ and $T_{2}$ may increase the binding energy of aptamer assembly to $\mathrm{H}_{1}$, which subsequently decreases the amplification efficiency of triggering HCR.

Cell lines. Human breast cancer cell lines (BT-474, MCF-7 and UACC-812) and human mammary epithelial cell line (MCF-10A) were obtained from American Type Culture Collection (ATCC, USA). BT-474 cells were cultured in DMEM. MCF-7 cells were cultured in RPMI-1640 medium. UACC-812 cells were cultured in L15 medium. MCF-10A cells were cultured in MEGM BulletKit (CC-3151 \& CC-4136) medium. All media were supplied with $10 \%$ FBS and $1 \%$ penicillin-streptomycin. All cells were incubated at $37{ }^{\circ} \mathrm{C}$ with $5 \% \mathrm{CO}_{2}$.

Flow cytometry analysis of co-expression of HER2 and EpCAM on cell membranes. Trypsinized BT-474, MCF-7, UACC-812 or MCF-10A cells $\left(2 \times 10^{5}\right.$ for each) were resuspended in cell culture medium for $6 \mathrm{~h}$ on a vortexer to enable subsequent aptamer labeling and flow cytometry analysis. The cells were then incubated with 500 nM HER2-Cy5 aptamer and 500 nM EpCAM-FAM aptamer, $500 \mathrm{nM}$ random-Cy5 sequence and $500 \mathrm{nM}$ random-FAM sequence, or nothing (control) in $200 \mu \mathrm{L}$ binding buffer $\left(0.1 \mathrm{mg} \mathrm{mL}^{-1}\right.$ yeast tRNA, $1 \mathrm{mg} \mathrm{mL}^{-1} \mathrm{BSA}, 4.5 \mathrm{~g}$ 
$\mathrm{L}^{-1}$ glucose and $5 \mathrm{mM} \mathrm{MgCl} 2$ in DPBS) on a vortexer for $1 \mathrm{~h}$ at $4{ }^{\circ} \mathrm{C}$. After incubation, the cells were washed 3 times with washing buffer $\left(4.5 \mathrm{~g} \mathrm{~L}^{-1}\right.$ glucose and $5 \mathrm{mM} \mathrm{MgCl}_{2}$ in DPBS) for flow cytometry analysis (NovoCyte 2060R, ACEA Biosciences, USA). 2000 events were counted for each sample. Flow cytometry data were analyzed by FlowJo software (V10). BT-474 cells showed the highest percentage of $42.3 \%$ for HER2+, EpCAM+ events, whereas MCF-7, UACC-812 and MCF-10A cells showed much lower percentages of $1.8 \%, 1.2 \%$ and $1 \%$, respectively. These results show that dual-aptamer labeling can correctly recognize the co-expression pattern of HER2 and EpCAM and lay the foundation for AND logic operation.

DNA logic computation on cell membranes. Trypsinized BT-474, MCF-7, UACC-812 or MCF-10A cells $\left(8 \times 10^{5}\right.$ for each) were incubated with $500 \mathrm{nM}$ EpCAM-S-T ${ }_{1}$ and $500 \mathrm{nM}$ HER2-S- $\mathrm{T}_{2}$ in $200 \mu \mathrm{L}$ binding buffer on a vortexer for 1 $\mathrm{h}$ at $4{ }^{\circ} \mathrm{C}$. After incubation, the cells were washed twice with washing buffer to remove excess Apt-S-T strands, and incubated with $2.5 \mu \mathrm{M}$ Connector, $1 \mu \mathrm{M} \mathrm{H_{1 }}$ and $1 \mu \mathrm{M} \mathrm{H}_{2}$ probes in $200 \mu \mathrm{L}$ binding buffer on a vortexer for $1.5 \mathrm{~h}$ at $4{ }^{\circ} \mathrm{C}$. After incubation, the cells were washed twice with washing buffer to remove excess Connector, $\mathrm{H}_{1}$ and $\mathrm{H}_{2}$ probes and finally transferred into $100 \mu \mathrm{L}$ washing buffer. 10 $\mu \mathrm{L}$ of cell suspension was dropped on a glass slide and covered with a slide for fluorescence observation under a confocal laser scanning microscope (LSM710, Zeiss, Germany) with a $40 \times$ objective. The fluorescence intensity of confocal 
images was quantified using ImageJ software (1.50i, NIH, USA).

The high signal output achieved on the cell membranes can be attributed to several reasons. First, the background signal of cell membranes is lower than that of solution, as leaky HCR products (caused by auto-hybridization of the metastable $\mathrm{H}_{1}$ and $\mathrm{H}_{2}$ ) can only exist in solution but not on cell membranes with our design. Second, multiple rounds of washing and separation of cells help eliminate the unspecific binding of fluorescently labeled $\mathrm{H}_{1}$ probe, which further decreases the background signals of cells. Both the above-mentioned reasons can help improve the $\mathrm{S} / \mathrm{N}$ ratio on cell membranes, given that the efficiency of $\mathrm{HCR}$ is not significantly different in solution and on cell membranes.

EV isolation. To isolate cell line-derived EVs, the cell culture media were collected until cells reached a confluency of $70 \%$. The collected media $(240 \mathrm{~mL})$ were centrifuged twice at $2000 \times \mathrm{g}$ for $10 \mathrm{~min}$ to remove cells and large cell debris. The supernatant was centrifuged at $10000 \times \mathrm{g}$ for $60 \mathrm{~min}$, processed by membrane filtration $(0.22 \mu \mathrm{m}$, Millipore, USA) and ultracentrifuged at $100000 \times \mathrm{g}$ for $3 \mathrm{~h}$. The EVs were collected by suspending the pellet in $1.6 \mathrm{~mL} 1 \times \mathrm{PBS}$ and stored at $-80{ }^{\circ} \mathrm{C}$ before use. To isolate EVs from clinical serum samples, serum $(0.26 \mathrm{~mL}$ for each individual) was diluted by 100 folds in $1 \times$ PBS and centrifuged at $2000 \times \mathrm{g}$ for 20 min to remove cell debris. The supernatant was processed by membrane filtration $(0.45 \mu \mathrm{m}$, Millipore, USA), and ultracentrifuged at $100000 \times \mathrm{g}$ for $3 \mathrm{~h}$. The serum EVs in each ultracentrifuge tubes were collected by suspending the pellet in 0.26 
$\mathrm{mL} 1 \times \mathrm{PBS}$, stored at $-80{ }^{\circ} \mathrm{C}$ before use. Before ultracentrifugation, the medium or diluted serum was packaged into eight ultracentrifuge tubes with the weight difference between every pair of tubes smaller than $0.05 \mathrm{~g}$.

Nanoparticle tracking analysis (NTA). To quantify the concentration and size distribution of EVs, EV samples were characterized using NTA (NanoSight NS300, Malvern Instrument, England) at $26 \pm 3{ }^{\circ} \mathrm{C}$. The concentrations of EV were adjusted to $\sim 10^{9}$ particles $\mathrm{mL}^{-1}$ before measurement to achieve optimal counting accuracy. The data of size distribution was captured and analyzed with the NTA 3.4 Analytical Software Suite.

Fluorescence co-localization analysis. To evaluate expression pattern of HER2 and EpCAM on EV membranes, EVs derived from BT-474, MCF-7, UACC-812 or MCF-10A cells were incubated with $50 \mathrm{nM}$ HER2-Cy5 aptamer and $50 \mathrm{nM}$ EpCAM-FAM aptamer on a vortexer for $2 \mathrm{~h}$ at $25^{\circ} \mathrm{C}$, followed by DiI $(1 \mu \mathrm{M})$ labeling on a vortexer for $10 \mathrm{~min}$ at $37^{\circ} \mathrm{C}$. The co-localization of Cy5, FAM and DiI fluorescence was observed under a $100 \times$ objective on a fluorescent microscope (DMi8, Leica, Germany) and recorded by an sCMOS camera (95B, Photometrics, Canada) with a $2 \times 2$ pixels binning and an exposure time of $50 \mathrm{~ms}$.

Modification of microbeads. Performing DNA computation on biological membranes requires multiple washing steps to remove unspecifically bound probes 
and to reduce background signal, ${ }^{1-2}$ which is challenging for EVs given their nanoscale size. Therefore, we used microbeads to capture EV to enable multiple washing steps by simple centrifugation, thus greatly improving signal-to-noise $(\mathrm{S} / \mathrm{N})$ ratio for logic operations on EV membranes. For EV capture, the streptavidin-coated polystyrene microbeads $(1.8 \mu \mathrm{m}$ in diameter $)$ were modified with biotinylated CD63 aptamer or biotinylated anti-CD63 antibody. For aptamer modification, $300 \mu \mathrm{L}$ microbeads $\left(3.7 \times 10^{5} \mu \mathrm{L}^{-1}\right)$ were washed twice with $300 \mu \mathrm{L}$ modification buffer $(20 \mathrm{mM}$ Tris, $\mathrm{pH} 7.5 ; 1 \mathrm{M} \mathrm{NaCl} ; 1 \mathrm{mM}$ EDTA; $0.0005 \%$ Triton $\left.^{\mathrm{TM}} \mathrm{X}-100\right)$, centrifuged at $10000 \times \mathrm{g}$ for $5 \mathrm{~min}$ and suspended in $60 \mu \mathrm{L}$ modification buffer. $30 \mu \mathrm{L}$ biotinylated CD63 aptamer $(100 \mu \mathrm{M})$ was added into the prepared microbeads $(60 \mu \mathrm{L})$, followed by incubation on a vortexer for $20 \mathrm{~min}$ at $25{ }^{\circ} \mathrm{C}$. The CD63-aptamer-modified microbeads were washed twice, suspended in $300 \mu \mathrm{L} 1 \times$ PBS and stored at $4{ }^{\circ} \mathrm{C}$ before use. Based on the instruction from manufacturer, 200 pmoles of aptamer can be modified on $1 \mathrm{mg}$ of microbeads, corresponding to $8.2 \times 10^{5}$ aptamer per microbead. For antibody modification, 100 $\mu \mathrm{L}$ microbeads $\left(3.7 \times 10^{5} \mu \mathrm{L}^{-1}\right)$ were washed twice with $200 \mu \mathrm{L}$ modification buffer, centrifuged at $10000 \times \mathrm{g}$ for $5 \mathrm{~min}$ and suspended in $200 \mu \mathrm{L}$ modification buffer. 15 $\mu \mathrm{L}$ biotinylated anti-CD63 antibody $\left(1 \mathrm{mg} \mathrm{mL}^{-1}\right)$ was added into the prepared microbeads $(200 \mu \mathrm{L})$, followed by incubation on a vortexer for $30 \mathrm{~min}$ at $25^{\circ} \mathrm{C}$. The anti-CD63-antibody-modified microbeads were washed twice, suspended in $200 \mu \mathrm{L} 1 \times$ PBS and stored at $4{ }^{\circ} \mathrm{C}$ before use. 
Optimization of microbead concentration. To visualize the capture efficiency of EVs, $10^{7} \mu \mathrm{L}^{-1}$ BT-474 EVs were incubated with DiI (1:1000) on a vortexer for 0.5 $\mathrm{h}$ at $37{ }^{\circ} \mathrm{C}$. The DiI-labeled EVs were mixed with CD63-aptamer-modified microbeads or anti-CD63-antibody-modified microbeads at different concentrations up to $3.7 \times 10^{5} \mu \mathrm{L}^{-1}$ in binding buffer and incubated on a vortexer for $2 \mathrm{~h}$ at $25^{\circ} \mathrm{C}$. The mixtures were centrifuged at $3000 \times \mathrm{g}$ for $10 \mathrm{~min}$ and the supernatant was transferred into a microchamber for fluorescence characterization of the remained EVs. Fluorescence was observed under a $40 \times$ objective on a fluorescent microscope (DMi8, Leica, Germany) and recorded by an sCMOS camera (95B, Photometrics, Canada) with a $2 \times 2$ pixels binning and an exposure time of $50 \mathrm{~ms}$. The capture efficiency was calculated as $\left(1-\mathrm{N}_{\mathrm{s}} / \mathrm{N}_{0}\right) \%$, where $\mathrm{N}_{\mathrm{s}}$ is the concentration of EVs remained in supernatant after capture and $\mathrm{N}_{0}$ is the initial EV concentration. The capture efficiency increased with the microbead concentration for both microbead types and achieved maximum of $89.5 \%$ for CD63-aptamer-modified microbeads and $78.1 \%$ for anti-CD63-antibody-modified microbeads at $3.7 \times 10^{4} \mu \mathrm{L}^{-1}$ (Figure S7). Further increase of microbead concentration did not achieve higher capture efficiency. As compared with CD63 antibody, CD63 aptamer with smaller size (2$3 \mathrm{~nm}$ in diameter) may efficiently recognize the EV surface markers owing to the lower steric hindrance. ${ }^{3-4}$ In addition, high thermo-stability renders aptamer compatible to thermophoretic signal amplification. Therefore, we used CD63-aptamer-modified microbeads $\left(3.7 \times 10^{4} \mu \mathrm{L}^{-1}\right)$ for the following DNA computation on EV membranes. 
Scanning electron microscopy (SEM). To observe the capture of EVs by microbeads, CD63-aptamer-modified microbeads $\left(3.7 \times 10^{4} \mu \mathrm{L}^{-1}\right)$ were incubated with $10^{7} \mu \mathrm{L}^{-1} \mathrm{BT}-474 \mathrm{EVs}$ in binding buffer on a vortexer for $2 \mathrm{~h}$ at $25^{\circ} \mathrm{C}$. The microbeads without CD63 aptamer modification were used as control. Microbead suspensions $(10 \mu \mathrm{L})$ before EV capture and after EV capture (with and without AND gate operation) were adsorbed on Formvar/carbon-coated copper grids for 10 min, followed by drying with filter paper. The grids were coated with a $3 \mathrm{~nm} \mathrm{Pt}$ layer to increase the contrast and observed on an SEM (S4800, Hitachi, Japan).

Transmission electron microscopy (TEM). TEM was used to observe the formation of HCR assembly on EV membranes after AND gate operation. BT-474 EVs $\left(10^{7} \mu \mathrm{L}^{-1}\right)$ were incubated with $500 \mathrm{nM}$ EpCAM-S-T 1 and $500 \mathrm{nM}$ HER2-S-T 2 probes for $2 \mathrm{~h}$ at $25{ }^{\circ} \mathrm{C}$, followed by washing and incubation with $2.5 \mu \mathrm{M}$ Connector, $5 \mu \mathrm{M} \mathrm{H}_{1}$ and $5 \mu \mathrm{M} \mathrm{H}_{2}$ probes for $18 \mathrm{~h}$ at $25^{\circ} \mathrm{C}$. The samples before and after AND gate operation were adsorbed on Formvar/carbon-coated copper grids for $2 \mathrm{~h}$, washed twice by DI water, stained by $2 \%$ phosphotungstic acid for $5 \mathrm{~min}$ and washed again by DI water. After air drying, the samples were observed on a Tecnai G2 20 S-TWIN TEM (FEI, USA) at $200 \mathrm{kV}$.

Dynamic light scattering (DLS). The surface zeta potentials ( $n=3$ for each microbead type) of unmodified microbeads, CD63-aptamer-modified microbeads 
and Cy5-CD63-aptamer-modified microbeads were measured using a Zetasizer (Malvern Nano ZS, Malvern Instruments Ltd, England).

Microchamber fabrication. The microchamber was fabricated by sandwiching a $400-\mu \mathrm{m}$-thick spacer with a circular hole $(7 \mathrm{~mm}$ in diameter) between a glass top layer (1 mm thick) and a sapphire bottom layer (1 mm thick).

Mechanism of thermophoretic accumulation. The thermophoretic accumulation of EV-conjugated microbeads relies on the interplay of thermophoresis and convection. By focusing an infrared laser beam into a thick fluid chamber, the presence of localized temperature gradient leads to the thermophoretic repulsion of microbeads away from the hot region, while the synergistic convention effect results in the transport of microbeads towards the center of chamber bottom. ${ }^{5}$ The balance between thermophoresis and convection contributes to a rapid accumulation of microbeads at the center of chamber bottom to amplify the output signal of AND gate operation.

Optimization of thermophoresis-mediated signal amplification. To visualize the performance in thermophoretic enrichment at different conditions, microbeads modified with Cy5-conjugated CD63 aptamers were used. To evaluate the impact of the ionic strength, $3.7 \times 10^{4} \mu \mathrm{L}^{-1}$ microbeads were suspended in $\mathrm{NaCl}$ solutions prepared at different concentrations $(0 \mathrm{mM}, 5 \mathrm{mM}, 10 \mathrm{mM}, 50 \mathrm{mM}$ and $100 \mathrm{mM})$ 
in DI water. The microbead suspension was subjected to $1480 \mathrm{~nm}$ laser heating (Changchun Laser Optoelectronics Technology, China) for $10 \mathrm{~min}$. For all the optimization experiments, the fluorescence images before and after laser irradiation were observed under a $20 \times$ objective (N.A. 0.22) on a fluorescent microscope (DMi8, Leica, Germany) and recorded by an sCMOS (95B, Photometrics, Canada) with a $2 \times 2$ pixels binning and an exposure time of $4 \mathrm{~ms}$. The fluorescence intensity after laser heating monotonically decreased with increasing $\mathrm{NaCl}$ concentration. It was thus necessary to fix EV-conjugated microbeads and transfer them into DI water before thermophoretic enrichment (Figure S11).

To optimize the chamber height, the microbeads $\left(3.7 \times 10^{4} \mu \mathrm{L}^{-1}\right)$ were suspended in DI water, loaded into a microchamber with different height $(320 \mu \mathrm{m}$, $400 \mu \mathrm{m}$ and $480 \mu \mathrm{m}$ ) and subjected to laser heating (laser power $185 \mathrm{~mW}$ ) for 10 min. Maximum fluorescence intensity was achieved at the chamber height of 400 $\mu \mathrm{m}$ (Figure S12a).

To optimize the laser power, the microbeads $\left(3.7 \times 10^{4} \mu \mathrm{L}^{-1}\right)$ were suspended in DI water, loaded into a 400- $\mu$ m-high microchamber and subjected to laser heating at different laser power (165 mW, $185 \mathrm{~mW}$ and $205 \mathrm{~mW})$ for $10 \mathrm{~min}$. Maximum fluorescence intensity was achieved at the laser power of $185 \mathrm{~mW}$ (Figure S12b).

To optimize the laser irradiation time, the microbeads $\left(3.7 \times 10^{4} \mu \mathrm{L}^{-1}\right)$ were suspended in DI water, loaded into a $400-\mu \mathrm{m}$-high microchamber and subjected to laser heating (laser power $185 \mathrm{~mW}$ ) for up to $18 \mathrm{~min}$. The fluorescence intensity reached the maximum at 16 min and did not further increase (Figure S13). 
Thermophoresis-mediated AND gate on cell line-derived EVs. EVs $\left(10^{7} \mu \mathrm{L}^{-1}\right)$ derived from BT-474, MCF-7, UACC-812 or MCF-10A cells were incubated with CD63-aptamer-modified microbeads $\left(3.7 \times 10^{4} \mu \mathrm{L}^{-1}\right), 500 \mathrm{nM}$ EpCAM-S- $\mathrm{T}_{1}$ and 500 nM HER2-S- $\mathrm{T}_{2}$ in binding buffer on a vortexer for $2 \mathrm{~h}$ at $25^{\circ} \mathrm{C}$. After incubation, the EV-conjugated microbeads were centrifuged at $2600 \times \mathrm{g}$ for $1 \mathrm{~min}$, followed by incubation with $2.5 \mu \mathrm{M}$ Connector, $100 \mathrm{nM} \mathrm{H}_{1}$ and $100 \mathrm{nM} \mathrm{H}_{2}$ on a vortexer for 1.5 h at $25{ }^{\circ} \mathrm{C}$. The occurrence of HCR was assessed by flow cytometric analyses of EV-conjugated microbeads by using various HCR time of $0 \mathrm{~h}, 0.5 \mathrm{~h}, 1 \mathrm{~h}, 1.5 \mathrm{~h}$ and $2 \mathrm{~h}$ (Figure S8a). The fluorescence intensity of EV-conjugated beads monotonically increased with HCR time and reached a plateau after $1.5 \mathrm{~h}$. However, the absolute fluorescence after $1.5 \mathrm{~h}$ of HCR was weak and cannot be used for quantification of HER2 + EpCAM+ EVs under microscopy imaging (Figure S8b). Therefore, we employed thermophoretic accumulation to amplify the HCR signals. The overall amplification efficiency after $\mathrm{HCR}$ and thermophoretic accumulation was determined to be 215 by calculating the fluorescence intensity ratio of EV-conjugated microbeads (Figure S8c). We should note that the HCR was performed on cell membranes at $4{ }^{\circ} \mathrm{C}$ to eliminate the background fluorescence signal resulting from the endocytosis of DNA probes. ${ }^{6-7}$ As EVs lack cellular machinery for endocytosis, the HCR was performed on EV membranes at a higher temperature of $25^{\circ} \mathrm{C}$ to improve catalytic efficiency for HCR reaction. ${ }^{8}$

For thermophoretic accumulation, the EV-conjugated microbeads after HCR 
were centrifuged at $2600 \times \mathrm{g}$ for $1 \mathrm{~min}$. The pellet was fixed by $4 \%$ paraformaldehyde for $30 \mathrm{~min}$, followed by adding $50 \mathrm{mM}$ glycine to stop fixation (the remained aptamer binding and HCR products were verified by flow cytometry analysis of EV-conjugated microbeads before and after fixation, Figure S10). To verify that the fixing step would not affect the aptamer binding and HCR product on the surface of EVs, we measured the fluorescence intensities of EV-conjugated microbeads after AND gate operation with or without fixation (4\% paraformaldehyde) using flow cytometry analysis. The fluorescence intensity of EV-conjugated microbeads after HCR and fixation exhibited no observable change (Figure S10). To eliminate the negative effect of ionic strength on thermophoretic accumulation, ${ }^{9}$ EV-conjugated microbeads after HCR were centrifuged $(2600 \times \mathrm{g}$ for $1 \mathrm{~min}$ ) and transferred to DI water. For thermophoretic amplification, $18 \mu \mathrm{L}$ samples were loaded into a $400-\mu \mathrm{m}$-high microchamber and subjected to laser heating (laser power $185 \mathrm{~mW}$ ) for $16 \mathrm{~min}$. The fluorescence images before and after laser irradiation were observed under a $20 \times$ objective (N.A. 0.22) on a fluorescent microscope (DMi8, Leica, Germany) and recorded by an sCMOS (95B, Photometrics, Canada) with a $2 \times 2$ pixels binning and an exposure time of $20 \mathrm{~ms}$.

Clinical sample collection. The clinical serum samples were collected from the Fifth Medical Centre, Chinese PLA General Hospital with informed consent and processed following the Early Detection Research Network (EDRN) standard operating procedure (SOP): (1) blood samples from patients were collected into 
acid citrate dextrose (ACD) serum separator tubes (yellow top) and the tubes were gently inverted for $5-8$ times, (2) the tubes were stored upright at $4{ }^{\circ} \mathrm{C}$ for $30 \mathrm{~min}$, (3) the tubes were centrifuged at $2000 \times \mathrm{g}$ for $30 \mathrm{~min}$, (4) serum samples were pipetted out into labeled centrifuge tubes and stored at $-80{ }^{\circ} \mathrm{C}$ until measurement. The patient status was summarized in Table S2.

Thermophoresis-mediated AND gate on serum EVs. To evaluate the performance of thermophoresis-mediated AND gate operation, serum EVs were isolated from a HER2 + BC patient and prepared in binding buffer at various concentrations of $2 \times 10^{3} \mu \mathrm{L}^{-1}, 2 \times 10^{4} \mu \mathrm{L}^{-1}, 2 \times 10^{5} \mu \mathrm{L}^{-1}, 4 \times 10^{5} \mu \mathrm{L}^{-1}, 1 \times 10^{6} \mu \mathrm{L}^{-1}, 2 \times 10^{6} \mu \mathrm{L}^{-1}$. Serum EVs were incubated with CD63-aptamer-modified microbeads $\left(3.7 \times 10^{4} \mu \mathrm{L}^{-1}\right), 500$ $\mathrm{nM}$ EpCAM-S-T ${ }_{1}$ and $500 \mathrm{nM}$ HER2-S- $\mathrm{T}_{2}$ on a vortexer for $2 \mathrm{~h}$ at $25^{\circ} \mathrm{C}$. To analyze the entire clinical cohort, aliquots of EVs isolated from $3.6 \mu \mathrm{L}$ serum were incubated with CD63-aptamer-modified microbeads $\left(3.7 \times 10^{4} \mu \mathrm{L}^{-1}\right), 500 \mathrm{nM}$ EpCAM-S-T $T_{1}$ and $500 \mathrm{nM}$ HER2-S-T $\mathrm{T}_{2}$ in binding buffer on a vortexer for $2 \mathrm{~h}$ at $25^{\circ} \mathrm{C}$. After incubation, the EV-conjugated microbeads were centrifuged at $2600 \times$

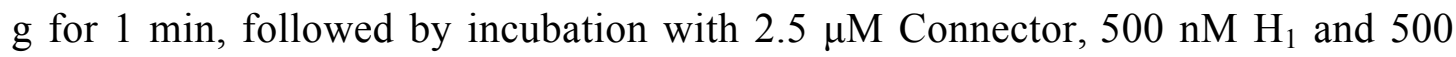
$\mathrm{nM} \mathrm{H}_{2}$ in binding buffer on a vortexer for $1.5 \mathrm{~h}$ at $25^{\circ} \mathrm{C}$. The EV-conjugated microbeads after HCR were centrifuged at $2600 \times \mathrm{g}$ for $1 \mathrm{~min}$. The pellet was fixed by $4 \%$ paraformaldehyde for $30 \mathrm{~min}$, followed by adding $50 \mathrm{mM}$ glycine to stop fixation and subsequent transfer into DI water. The procedures for thermophoretic assay and fluorescence imaging were as previously described in AND gate on cell 
line-derived EVs. To compare the sensitivity of thermophoresis and flow cytometry analysis, EV-conjugated microbeads after HCR were detected using a flow cytometer (BD, Accuri C6, USA). $10 \mu \mathrm{L}$ microbead suspension was used for each serum EV concentration. Flow cytometry data were analyzed by FlowJo software (V10).

Analysis of clinical results. In this study, the accuracy for classification of HER2+ BC versus HER2- BC was $90 \%$. We noted that several HER2- BC samples showed higher output signals after thermophoresis-mediated DNA computation (Figure S17). This phenomenon might be associated with several reasons. First, the stratification of HER2 status for BC patients was based on the immunohistochemistry and in-situ-hybridization (ISH) performed on tumor tissue. HER2- is defined as no staining or partial, weak staining at the cell membrane, which indicates no or weak expression of HER2 protein on tumor cells. Therefore, HER2- BC tumor may also secrete HER2+ EVs. Second, different sampling sources and time, i.e., tumor tissue and circulating EVs in blood, may inevitably lead to minor discrepancy results due to the strong heterogeneity of tumors. Similar discrepancy has also been observed in blood-based ctDNA or CTC for determining different genetic or phenotypic status as compared with tissue biopsy. ${ }^{10-11}$

Statistical analysis. The significance of difference in the signal intensities and expression levels from different groups of samples was tested using a two-tailed 
$t$-test (Figure 3d) or two-tailed Mann-Whitney U-test (Figure 4c). To evaluate the performance in $\mathrm{BC}$ diagnosis and molecular phenotyping, receiver operating characteristic (ROC) analysis was carried out. In BC versus HD discrimination, false positive rate was defined as the percentage of HDs that were classified as BC patients and false negative rate was defined as the percentage of $\mathrm{BC}$ patients that were classified as HDs. In HER2+ BC versus HER2- discrimination, false positive rate was defined as the percentage of HER2- BC patients that were classified as HER2 + BC patients and the false negative rate was defined as the percentage of HER2+ BC patients that were classified as HER2- BC patients. Significance analyses, construction of ROC curve and calculation of area under the curve (AUC) were performed using GraphPad Prism 7 (GraphPad, USA). 
Table S1. Summary of sequences.

\begin{tabular}{|c|c|}
\hline Sequence name & Sequence (5'-3') \\
\hline EpCAM-S- $T_{1}$ & $\begin{array}{l}\text { GACCCTAAGCATACATCAGCCTAATCGCACTGACGCTAGGT } \\
\text { TTTTTTTTTTTTTTCACTACAGAGGTTGCGTCTGTCCCACGT } \\
\text { TGTCATGGGGGGTTGGCCTG }\end{array}$ \\
\hline HER2-S-T 2 & $\begin{array}{l}\text { GGGCCGTCGAACACGAGCATGGTGCGTGGACCTAGGATGA } \\
\text { CCTGAGTACTGTCCTTTTTTTTTTTTTTTCGACATCTAACCTG } \\
\text { ATTAGGCTGCGTCCTTCAT }\end{array}$ \\
\hline Connector & CTTACAACACCTAGCGTCAGTGCGATCAGGTTAGATGTCG \\
\hline $\mathrm{H}_{1}$ & $\begin{array}{l}\text { Cy5-ATGAAGGACGATGTATGCTTAGGGTCGACTTCCATAGA } \\
\text { CCСTAAGCATACAT-BHQ3 }\end{array}$ \\
\hline $\mathrm{H}_{2}$ & $\begin{array}{l}\text { GACCCTAAGCATACATCGTCCTTCATATGTATGCTTAGGGT } \\
\text { CTATGGAAGTC }\end{array}$ \\
\hline $\begin{array}{l}\text { ssDNA } \\
\text { initiator }\end{array}$ & GACCCTAAGCATACATCGTCCTTCAT \\
\hline Biotin-CD63 & Biotin-CACCCCACCTCGCTCCCGTGACACTAATGCTA \\
\hline $\begin{array}{l}\text { Biotin-CD63- } \\
\quad \text { Cy5 }\end{array}$ & Biotin-CACCCCACCTCGCTCCCGTGACACTAATGCTA-Cy5 \\
\hline HER2-Cy5 & $\begin{array}{l}\text { GGGCCGTCGAACACGAGCATGGTGCGTGGACCTAGGATGA } \\
\text { CCTGAGTACTGTCC/iSpC12/-Сy5 }\end{array}$ \\
\hline EpCAM-FAM & $\begin{array}{l}\text { CACTACAGAGGTTGCGTCTGTCCCACGTTGTCATGGGGGGT } \\
\text { TGGCCTG/iSpC12/-FAM }\end{array}$ \\
\hline Random-Cy5 & CACCCCACCTAAAAAAAAAAACACTAATGCTA/iSpC12/-Cy5 \\
\hline Random-FAM & $\begin{array}{l}\text { CACCCCACCTAAAAAAAAAAACACTAATGCTA/iSpC12/-FA } \\
\text { M }\end{array}$ \\
\hline
\end{tabular}


Table S2. Summary of breast cancer (BC) patients and healthy donors (HD).

\begin{tabular}{|c|c|c|c|}
\hline Patient & Age & Stage & $\begin{array}{c}\text { HER2 status } \\
\text { (Immunohistochemistry) }\end{array}$ \\
\hline BC 1 & 46 & III & HER2+ \\
\hline BC 2 & 57 & III & HER2+ \\
\hline BC 3 & 46 & IV & HER2+ \\
\hline BC 4 & 63 & IV & HER2+ \\
\hline BC 5 & 50 & IV & HER2+ \\
\hline BC 6 & 36 & IV & HER2+ \\
\hline BC 7 & 56 & IV & HER2+ \\
\hline BC 8 & 49 & IV & HER2+ \\
\hline BC 9 & 54 & IV & HER2+ \\
\hline BC 10 & 57 & IV & HER2+ \\
\hline BC 11 & 50 & IV & HER2+ \\
\hline BC 12 & 47 & IV & HER2+ \\
\hline BC 13 & 46 & IV & HER2- \\
\hline BC 14 & 46 & IV & HER2- \\
\hline BC 15 & 58 & IV & HER2- \\
\hline BC 16 & 60 & IV & HER2- \\
\hline BC 17 & 38 & IV & HER2- \\
\hline BC 18 & 47 & IV & HER2- \\
\hline BC 19 & 65 & IV & HER2- \\
\hline BC 20 & 59 & IV & HER2- \\
\hline HD 1 & 55 & - & - \\
\hline HD 2 & 56 & - & - \\
\hline HD 3 & 49 & - & - \\
\hline HD 4 & 48 & - & - \\
\hline HD 5 & 51 & - & - \\
\hline HD 6 & 27 & - & - \\
\hline HD 7 & 67 & - & - \\
\hline HD 8 & 28 & - & - \\
\hline HD 9 & 49 & - & - \\
\hline HD 10 & 44 & - & - \\
\hline
\end{tabular}


Table S3. Performance of thermophoresis-mediated DNA computation in classifying HER2+ BC, HER2- BC and HD (95\% CIs are indicated in parentheses).

\begin{tabular}{ccccc}
\hline Groups & Sensitivity (\%) & Specificity (\%) & Accuracy (\%) & AUC \\
\hline $\begin{array}{c}\text { BC versus } \\
\text { HD }\end{array}$ & 95 & 100 & 97 & 0.99 \\
HER2+ BC & $(75-100)$ & $(69-100)$ & $(83-100)$ & $(0.98-1.00)$ \\
versus & 100 & 75 & & 0.94 \\
HER2- BC & $(74-100)$ & $(35-97)$ & $(68-99)$ & $(0.83-1.00)$ \\
\hline
\end{tabular}




\section{Supplementary Figures}

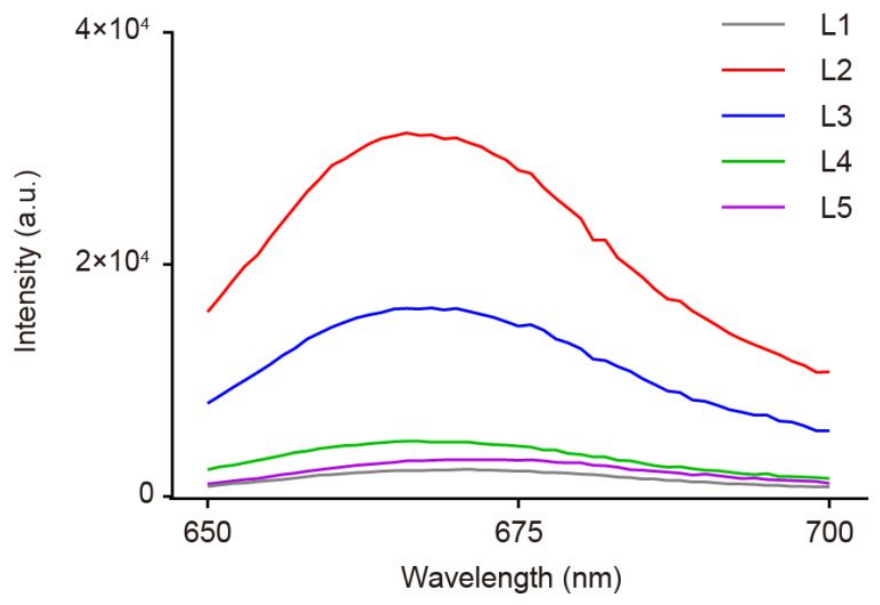

Figure S1. Fluorescence spectra of associative toehold-triggered HCR under different conditions $\left(n=3\right.$, mean \pm s.d.). L1: $\mathrm{H}_{1}+\mathrm{H}_{2}$; L2: ssDNA initiator $+\mathrm{H}_{1}+\mathrm{H}_{2}$; L3: EpCAM-S- $\mathrm{T}_{1}+$ HER2-S- $\mathrm{T}_{2}+$ Connector $+\mathrm{H}_{1}+\mathrm{H}_{2}$; L4: EpCAM-S-T $1+$ HER2-S-T 2 $+\mathrm{H}_{1}+\mathrm{H}_{2}$; L5: EpCAM-S-T $1+\mathrm{H}_{1}+\mathrm{H}_{2} . \mathrm{H}_{1}$ probe was labeled with Cy5 and BHQ3. 


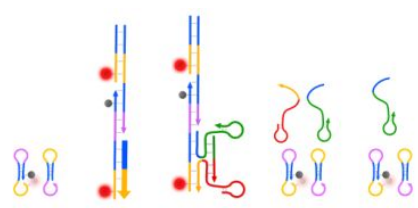

UV

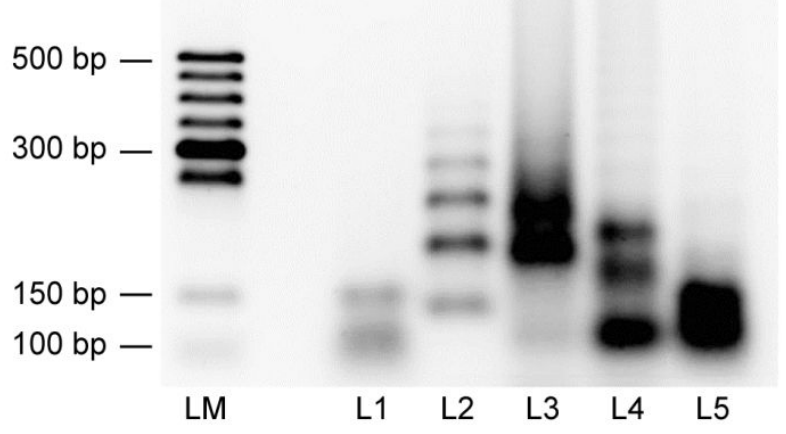

Figure S2. Validation of AND gate by gel electrophoresis. LM: 50 bp marker; L1: $\mathrm{H}_{1}$

$+\mathrm{H}_{2} ; \mathrm{L} 2$ : ssDNA initiator $+\mathrm{H}_{1}+\mathrm{H}_{2}$; L3: EpCAM-S-T $1+$ HER2-S-T $2+$ Connector + $\mathrm{H}_{1}+\mathrm{H}_{2}$; L4: EpCAM-S-T $1+$ HER2-S-T ${ }_{2}+\mathrm{H}_{1}+\mathrm{H}_{2}$; L5: EpCAM-S-T ${ }_{1}+\mathrm{H}_{1}+\mathrm{H}_{2}$. 


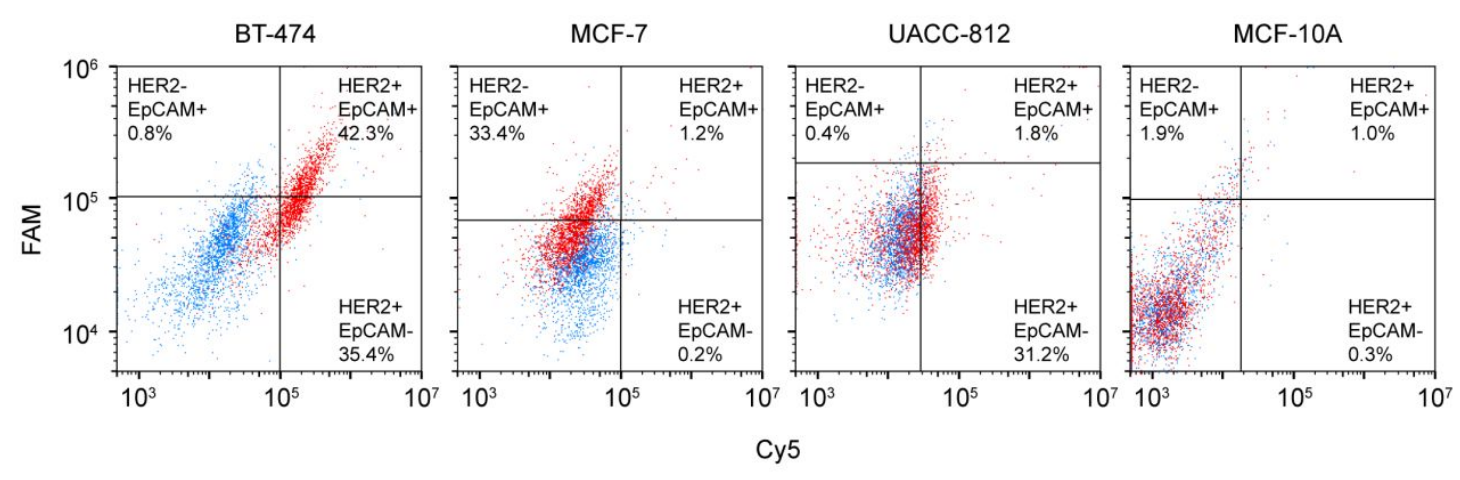

Figure S3. Co-expression of HER2 and EpCAM on cell membranes by flow cytometry analysis. Cells were labeled with Cy5-mofidied HER2 aptamer and FAM-modified EpCAM aptamer. The expression patterns for BT-474, MCF-7, UACC-812 and MCF-10A cells were HER2+, EpCAM+; HER2-, EpCAM+; HER2-, EpCAM+; HER2-, EpCAM-, respectively. 


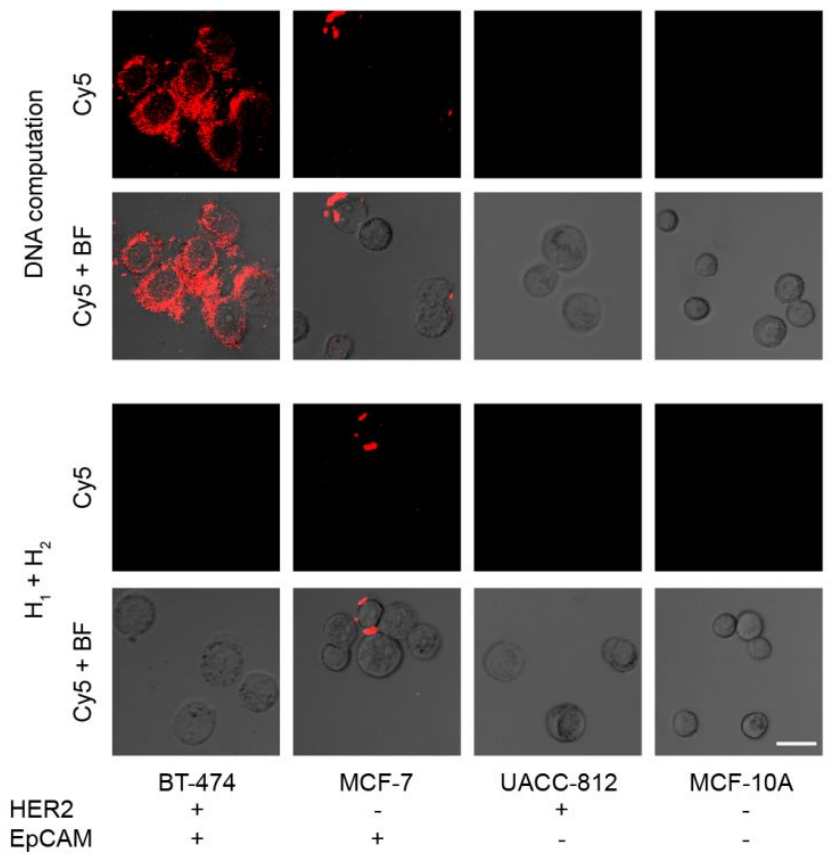

Figure S4. Fluorescence microscopy and bright-field (BF) overlay images of BT-474, MCF-7, UACC-812 and MCF-10A cells after AND gate operation (top) and after incubation with $\mathrm{H}_{1}+\mathrm{H}_{2}$ (control, bottom). Scale bar, $20 \mu \mathrm{m}$. 

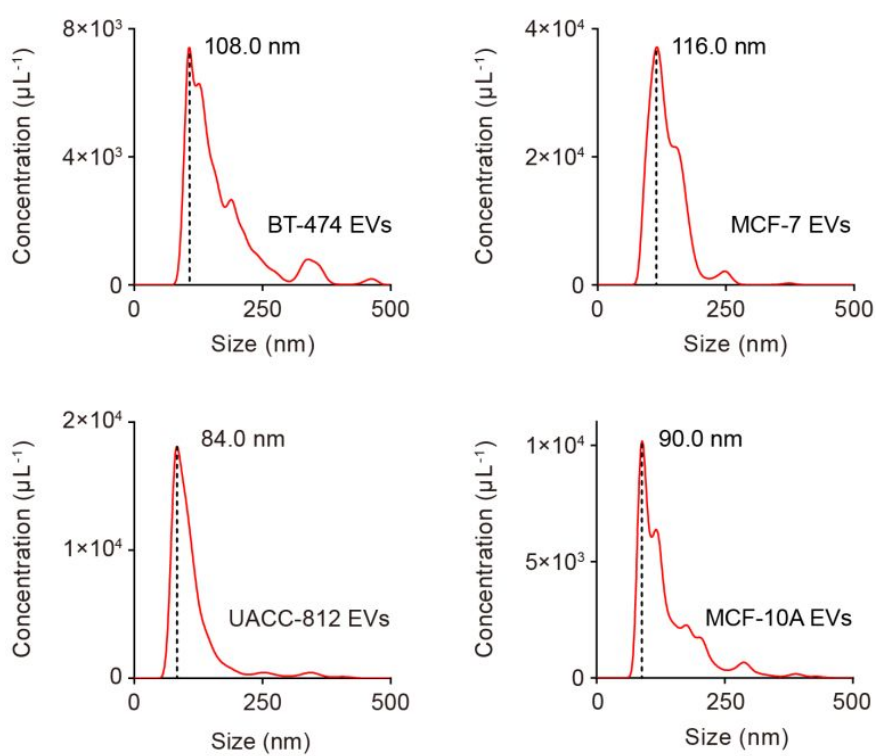

Figure S5. Size distribution of EVs derived from BT-474, MCF-7, UACC-812 and MCF-10A cells measured by NTA. 


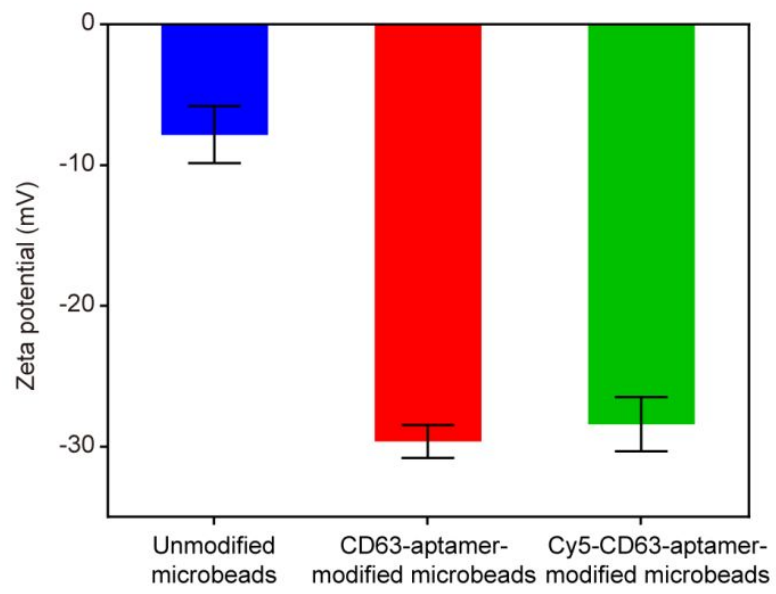

Figure S6. Zeta potential of unmodified microbeads and CD63-aptamer-modified microbeads measured in $1 \times$ PBS at $25^{\circ} \mathrm{C}(n=3$, mean \pm s.d. $)$. The modification of CD63 aptamer resulted in more negatively charged microbead surface and Cy5 labeling of CD63 aptamer did not affect the zeta potential of microbeads. 

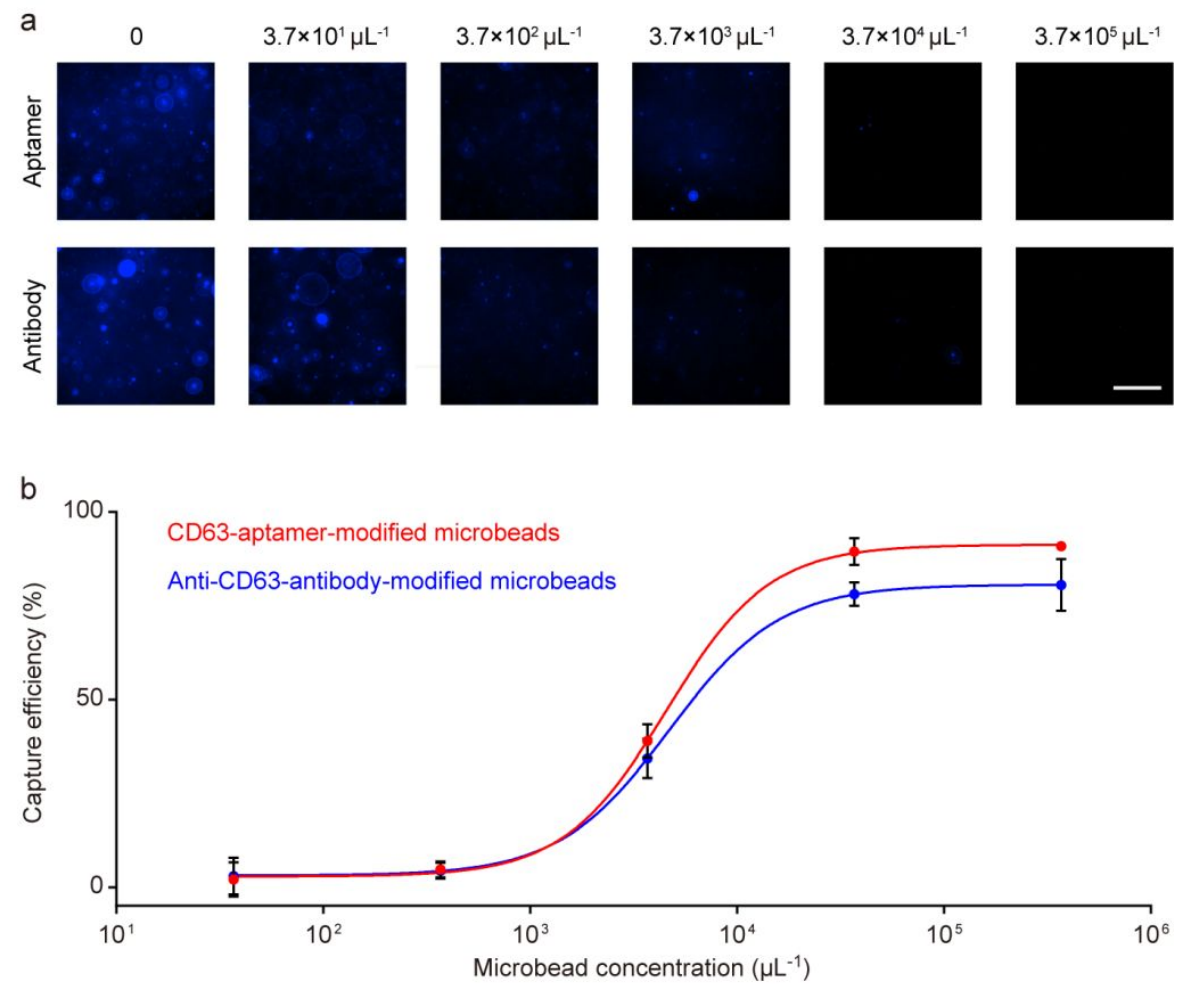

Figure S7. Optimization of microbead concentration for EV capture. (a) DiI-labeled BT-474 EVs remained in the supernatant after capture by different concentrations of microbeads. Initial EV concentration was $10^{7} \mu \mathrm{L}^{-1}$. Scale bar, $100 \mu \mathrm{m}$. (b) Capture efficiency of BT-474 EVs calculated for different concentrations of CD63-aptamer-modified microbeads and anti-CD63-antibody-modified microbeads $(n=3$, mean \pm s.d. $)$. 

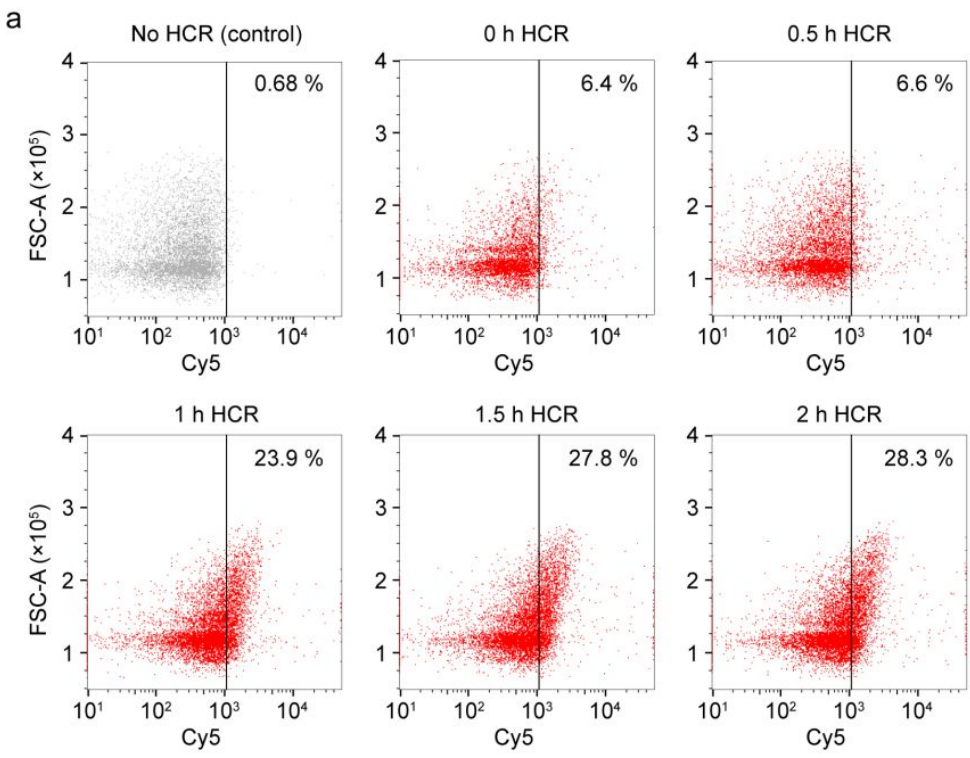

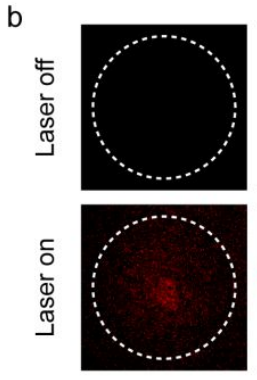

$\mathrm{Oh}$

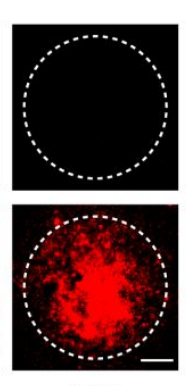

$1.5 \mathrm{~h}$

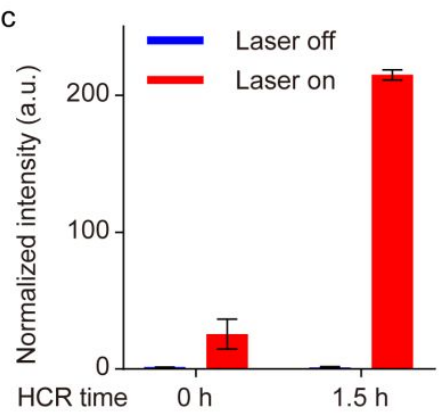

Figure S8. HCR kinetics for DNA computation on EV membranes. (a) Scatter plot of BT-474 EV-conjugated microbeads after different HCR time by flow cytometry analysis ( $n=3$, mean \pm s.d.). EV-conjugated microbeads without DNA computation were used as control. (b) Fluorescence images and (c) intensities of EV-conjugated microbeads after 0 or $1.5 \mathrm{~h}$ of $\mathrm{HCR}$ and the subsequent thermophoretic signal amplification. Scale bar, $30 \mu \mathrm{m}$. 


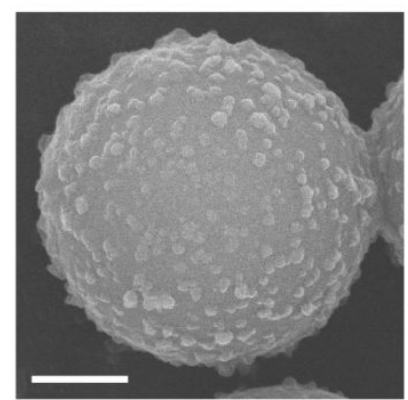

Figure S9. SEM imaging showing that BT-474 EVs of clear round morphology were still bound to the surfaces of CD63-aptamer-modified microbeads at high density after AND gate operation. Scale bar, $500 \mathrm{~nm}$. 

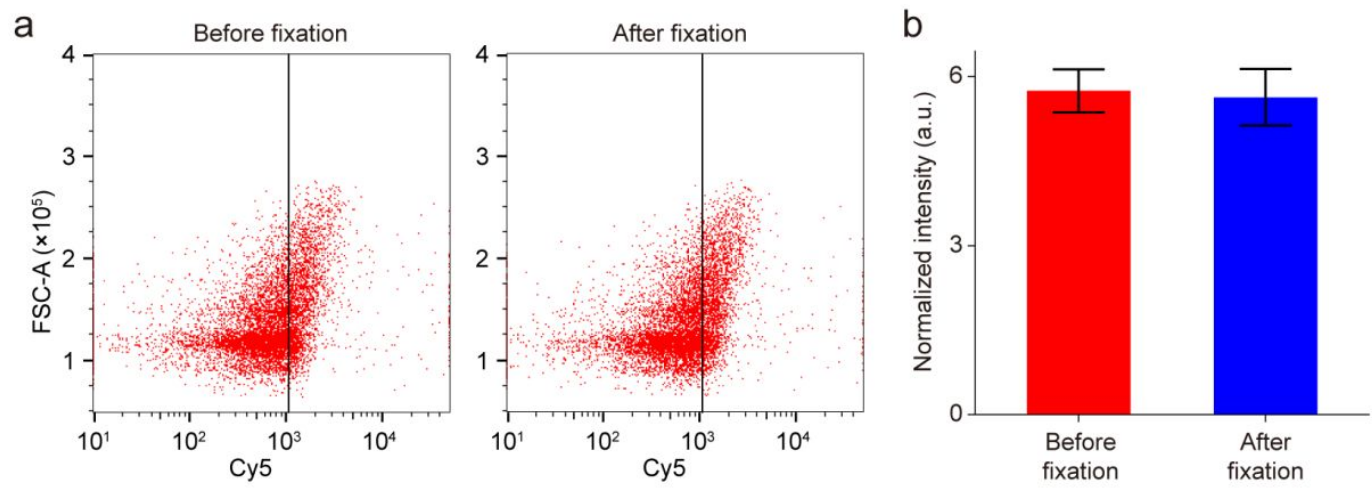

Figure S10. Flow cytometry analysis of EV-conjugated microbeads after AND gate operation with or without fixation. (a) Scatter plot and (b) fluorescence intensity of BT-474 EV-conjugated microbeads after AND gate operation with or without $4 \%$ paraformaldehyde fixation ( $n=3$, mean \pm s.d.). The intensities were normalized against that of EV-conjugated microbeads after $0 \mathrm{~h}$ HCR. 


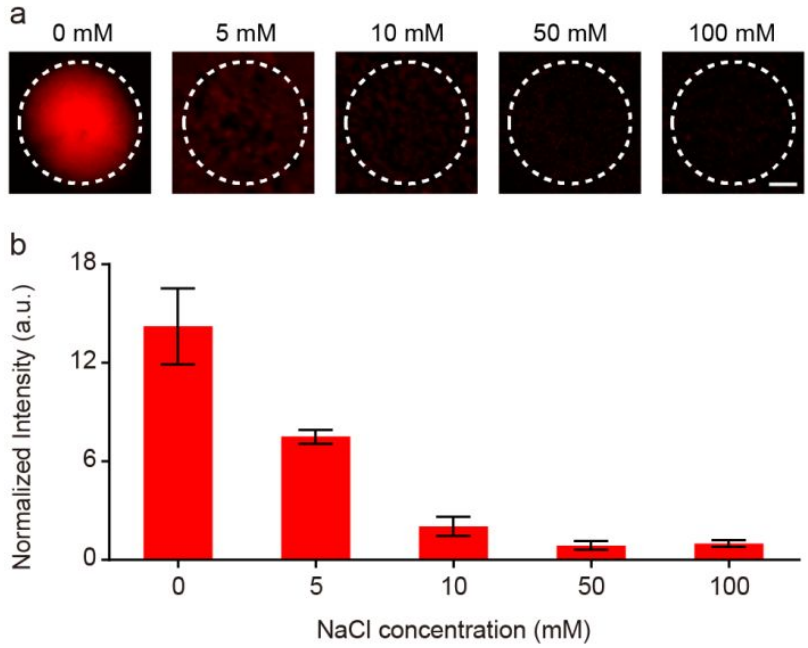

Figure S11. Effect of ionic strength on thermophoretic enrichment. (a) Fluorescence images and (b) fluorescence intensities of thermophoretic accumulation of Cy5-labeled microbeads in aqueous solutions of $\mathrm{NaCl}$ at different concentrations $(n=$ 3 , mean \pm s.d.). Scale bar, $30 \mu \mathrm{m}$. 

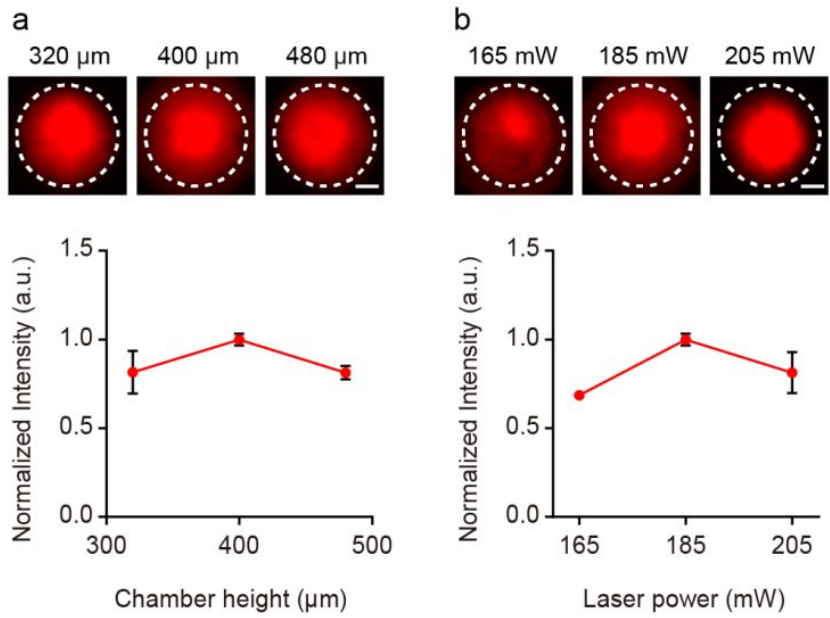

Figure S12. Optimization of chamber height and laser power. (a) Fluorescence images and fluorescence intensities of thermophoretic accumulation of Cy5-labeled microbeads in microchambers with different heights $(n=3$, mean \pm s.d.). The laser power was $185 \mathrm{~mW}$. (b) Fluorescence images and fluorescence intensities of thermophoretic accumulation of Cy5-labeled microbeads using different laser powers ( $n=3$, mean \pm s.d.). The chamber height was $400 \mu \mathrm{m}$. Scale bars, $30 \mu \mathrm{m}$. 

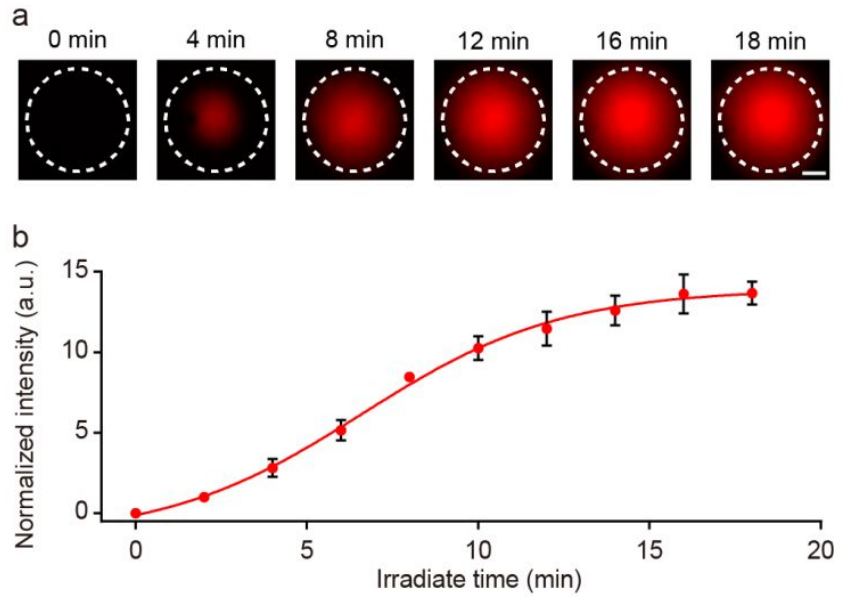

Figure S13. (a) Fluorescence images and (b) fluorescence intensities of thermophoretic accumulation of Cy5-labeled microbeads as a function of laser irradiation time ( $n=3$, mean \pm s.d.). Scale bar, $30 \mu \mathrm{m}$. 


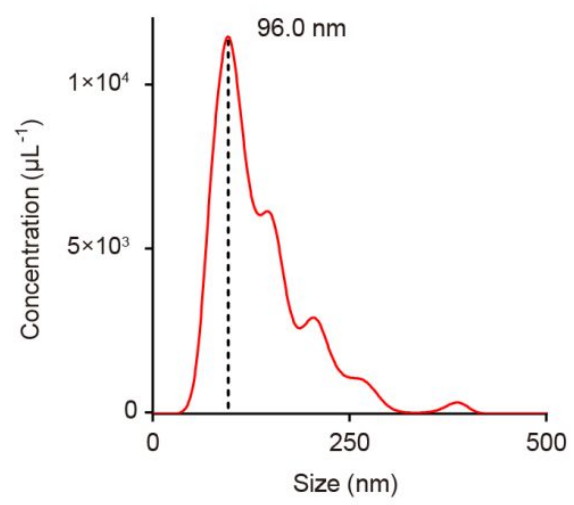

Figure S14. NTA characterization of the size distribution of serum EVs from a HER2+ BC patient. 


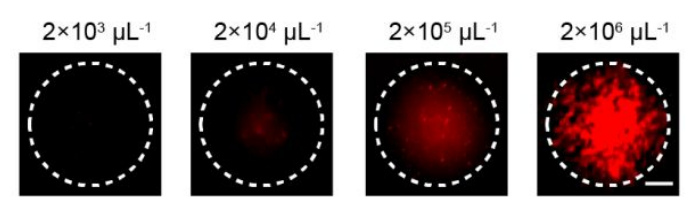

Figure S15. Thermophoresis-mediated DNA computation on serum EV membranes.

AND gate operation based on the expression pattern of HER2 and EpCAM was performed using serum EVs $\left(2 \times 10^{3}-2 \times 10^{6} \mu \mathrm{L}^{-1}\right)$ from a HER2+ BC patient. The EV-conjugated microbeads after HCR were subjected to thermophoretic enrichment. Scale bar, $30 \mu \mathrm{m}$. 

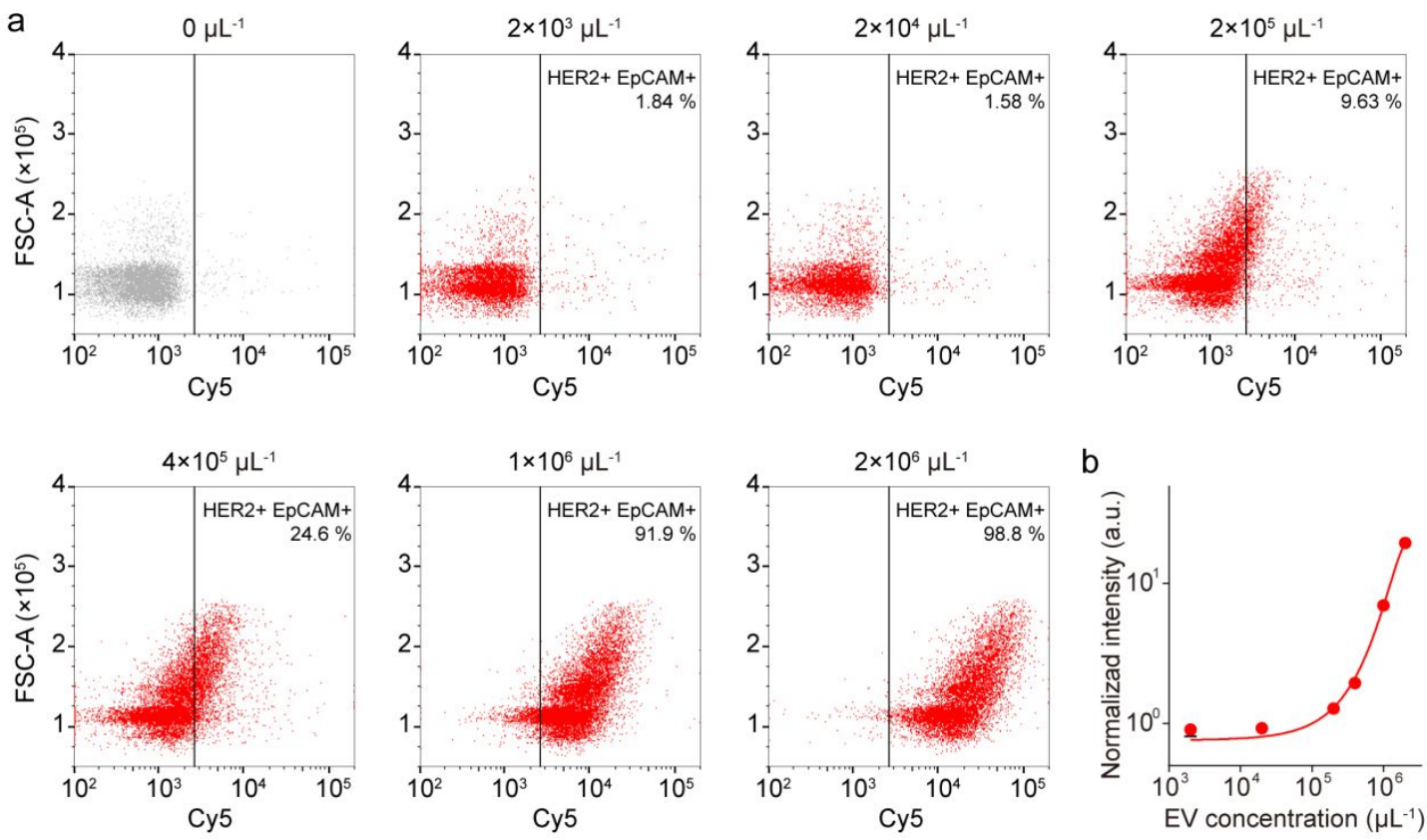

Figure S16. DNA computation on serum EV membranes by flow cytometry analysis.

(a) AND gate operation based on the expression pattern of HER2 and EpCAM was performed using serum EVs $\left(2 \times 10^{2}-2 \times 10^{6} \mu \mathrm{L}^{-1}\right)$ from a HER2+ BC patient. The fluorescence of EV-conjugated microbeads after HCR and bare microbeads (control, gray) were quantified by flow cytometry. (b) Mean fluorescence intensity of EV-conjugated microbeads after HCR. The intensities were normalized against the value of the control. 


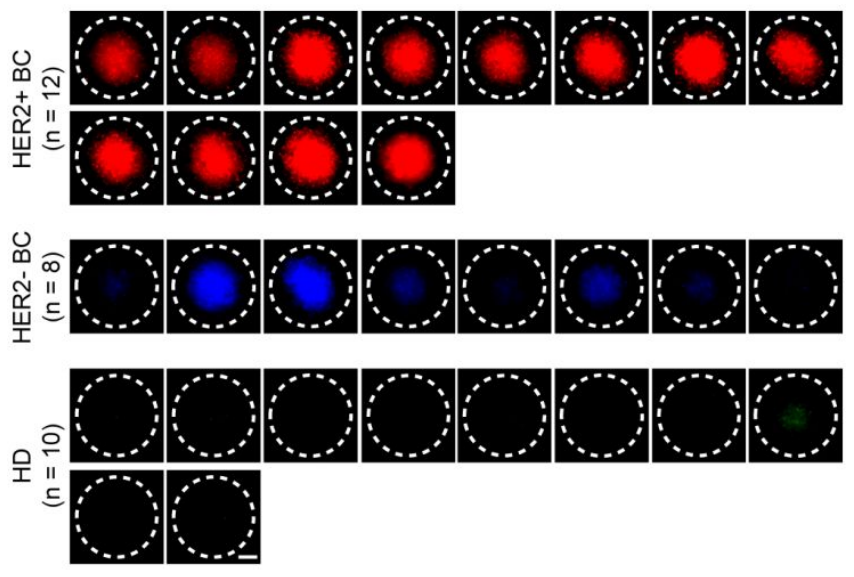

Figure S17. Fluorescence images of thermophoresis-mediated DNA computation on EVs from clinical serum samples. The clinical cohort included 12 HER2+ BC patients (red), 8 HER2- BC patients (blue) and 10 HDs (green). Scale bar, $30 \mu \mathrm{m}$. 


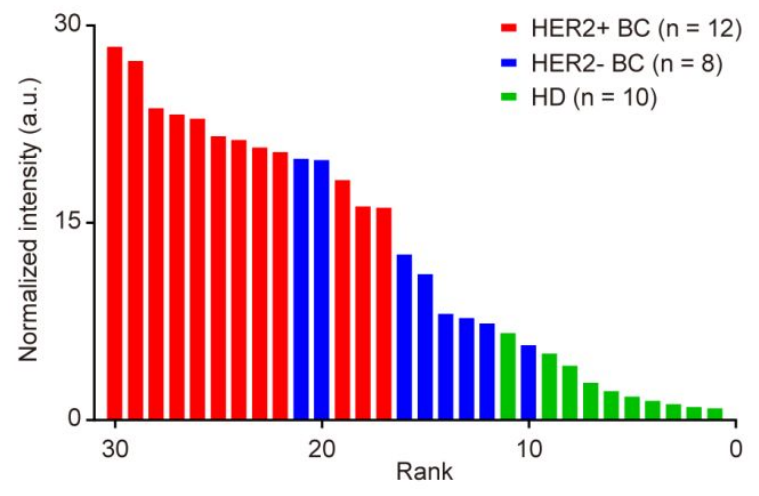

Figure S18. Waterfall plots of fluorescence intensities in a clinical cohort $(n=12$ for HER2 $+\mathrm{BC}, n=8$ for HER2- BC and $n=10$ for HD) sorted from high (left) to low (right). The different colors represent the fluorescent signals from EVs with different protein expression types. 


\section{References}

(1) Koos, B.; Cane, G.; Grannas, K.; Löf, L.; Arngården, L.; Heldin, J.; Clausson, C.-M.; Klaesson, A.; Hirvonen, M. K.; de Oliveira, F. M. S.; Talibov, V. O.; Pham, N. T.; Auer, M.; Danielson, U. H.; Haybaeck, J.; Kamali-Moghaddam, M.; Söderberg, O., Proximity-dependent initiation of hybridization chain reaction. Nat. Commun. 2015, 6, 7294.

(2) Li, J.; Liu, S.; Sun, L.; Li, W.; Zhang, S.-Y.; Yang, S.; Li, J.; Yang, H.-H., Amplified Visualization of Protein-Specific Glycosylation in Zebrafish via Proximity-Induced Hybridization Chain Reaction. J. Am. Chem. Soc. 2018, 140, 16589-16595.

(3) Huang, M.; Yang, J.; Wang, T.; Song, J.; Xia, J.; Wu, L.; Wang, W.; Wu, Q.; Zhu, Z.; Song, Y.; Yang, C., Homogeneous, Low-volume, Efficient, and Sensitive Quantitation of Circulating Exosomal PD-L1 for Cancer Diagnosis and Immunotherapy Response Prediction. Angew. Chem. Int. Ed. 2020, 59, 4800-4805.

(4) Labib, M.; Green, B.; Mohamadi, R. M.; Mepham, A.; Ahmed, S. U.; Mahmoudian, L.; Chang, I. H.; Sargent, E. H.; Kelley, S. O., Aptamer and Antisense-Mediated Two-Dimensional Isolation of Specific Cancer Cell Subpopulations. J. Am. Chem. Soc. 2016, 138, 2476-2479.

(5) Braun, D.; Libchaber, A., Trapping of DNA by Thermophoretic Depletion and Convection. Phys. Rev. Lett. 2002, 89, 188103.

(6) Chang, X.; Zhang, C.; Lv, C.; Sun, Y.; Zhang, M.; Zhao, Y.; Yang, L.; Han, D.; Tan, W., Construction of a Multiple-Aptamer-Based DNA Logic Device on Live Cell 
Membranes via Associative Toehold Activation for Accurate Cancer Cell Identification. J. Am. Chem. Soc. 2019, 141, 12738-12743.

(7) Tang, J.; Lei, Y.; He, X.; Liu, J.; Shi, H.; Wang, K., Recognition-Driven Remodeling of Dual-Split Aptamer Triggering In Situ Hybridization Chain Reaction for Activatable and Autonomous Identification of Cancer Cells. Anal. Chem. 2020, 92, 10839-10846.

(8) He, F.; Liu, H.; Guo, X.; Yin, B.-C.; Ye, B.-C., Direct Exosome Quantification via Bivalent-Cholesterol-Labeled DNA Anchor for Signal Amplification. Anal. Chem. 2017, 89, 12968-12975.

(9) Duhr, S.; Braun, D., Why molecules move along a temperature gradient. Proc. Natl. Acad. Sci. U. S. A. 2006, 103, 19678-19682.

(10) Aggarwal, C.; Thompson, J. C.; Black, T. A.; Katz, S. I.; Fan, R.; Yee, S. S.; Chien, A. L.; Evans, T. L.; Bauml, J. M.; Alley, E. W.; Ciunci, C. A.; Berman, A. T.; Cohen, R. B.; Lieberman, D. B.; Majmundar, K. S.; Savitch, S. L.; Morrissette, J. J. D.; Hwang, W.-T.; Elenitoba-Johnson, K. S. J.; Langer, C. J.; Carpenter, E. L., Clinical Implications of Plasma-Based Genotyping With the Delivery of Personalized Therapy in Metastatic Non-Small Cell Lung Cancer. JAMA Oncol. 2019, 5, 173-180. (11) Liu, Y.; Liu, Q.; Wang, T.; Bian, L.; Zhang, S.; Hu, H.; Li, S.; Hu, Z.; Wu, S.; Liu, B.; Jiang, Z., Circulating tumor cells in HER2-positive metastatic breast cancer patients: a valuable prognostic and predictive biomarker. BMC Cancer 2013, 13, 202. 